\title{
A HOMOGENIZER WITH REPLACEABLE RAZOR BLADES FOR BULK ISOLATION OF ACTIVE BARLEY PLASTIDS
}

\author{
by \\ C. GAMINI KANNANGARA, SIMON P. GOUGH, BENT HANSEN, \\ JAN N. RASMUSSEN and DAVID J. SIMPSON \\ Department of Physiology, Carlsberg Laboratory, \\ Gamle Carlsberg Vej 10, DK-2500 Copenhagen, Valby
}

Keywords: Chloroplast, etioplast, spinach, ultrastructure

A modification of the cutting device of a kitchen homogenizer is described which allows the preparation of biochemically active greening barley plastids. The new cutting device consists of four easily replaceable razor blades. Intact plastids are isolated from the immature leaves of spinach or from greening barley leaves with a yield of $10 \%$ and from etiolated barley with a yield of $6 \%$.

\section{INTRODUCTION}

The isolation of plastids from barley and other grasses has been difficult because of their high fibre content. Although intact plastids have been successfully isolated from barley using a mortar and pestle technique (2) this method is not suitable for preparing large amounts of intact plastids. Existing mechanical cutting devices damage the plastids during isolation due to development of local frictional heat and shear stresses (4). In order to overcome these difficulties and to rapidly prepare large amounts of intact plastids from greening barley, we have adapted a kitchen homogenizer. The principle of the modification is to change the original cutting device so that easily replaceable razor blades can be used. In this paper we detail the construction of the device and describe the properties of plastids prepared using it. 


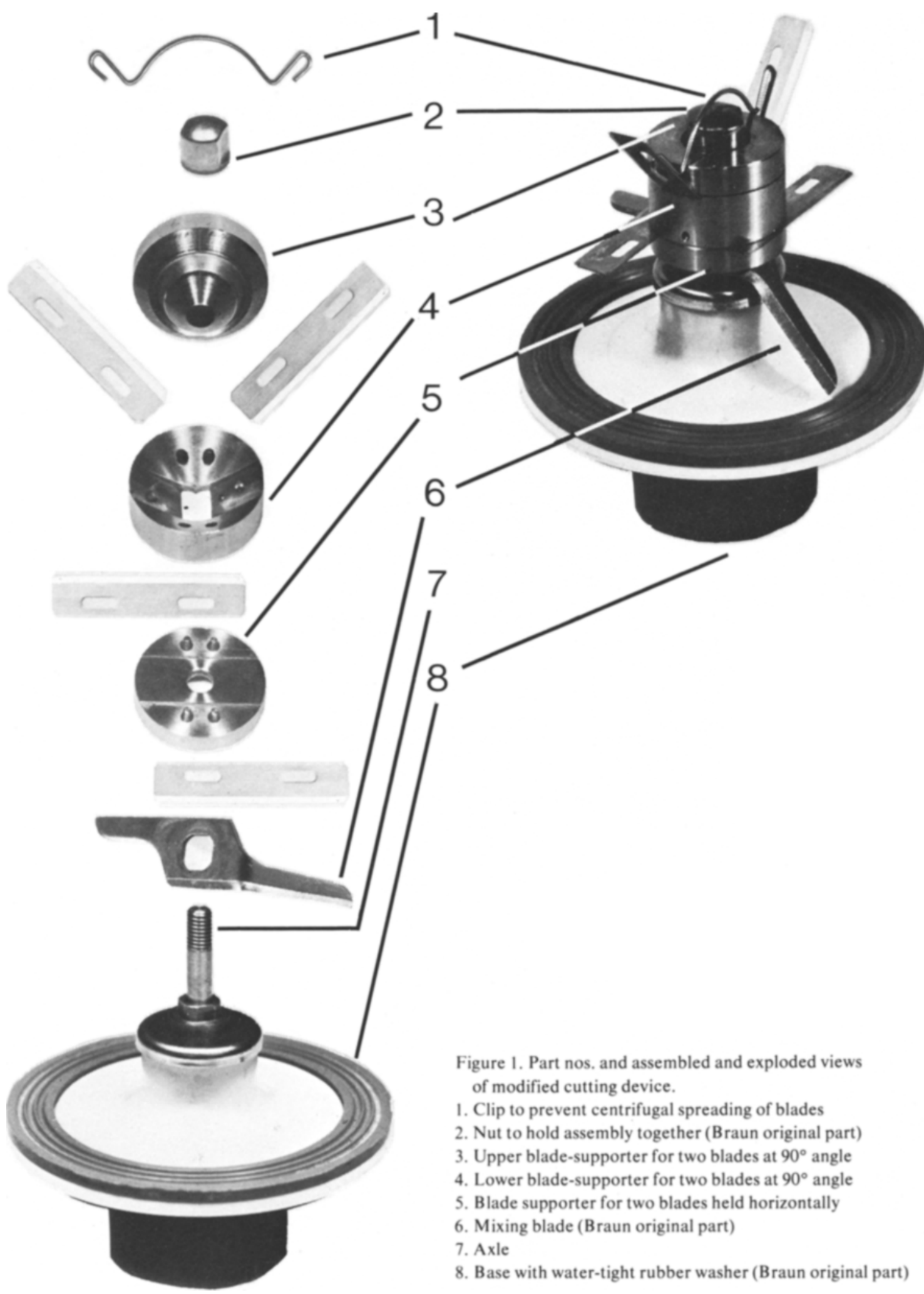




\section{CONSTRUCTION OF THE CUTTING DEVICE}

A kitchen homogenizer was readily modified to hold razor blades. The modified cutting unit is shown assembled and in its constituent parts in Figure 1. The original base with its rubber washer is retained, although the axle (part no. 7) has been lengthened to accommodate the new parts. The original lowest blade of the cutting device (part no. 6) has been retained to stir up debris at the bottom of the vessel during homogenization. On top of this is laid the bladesupporter (part no. 5) for the two horizontal razor blades. The razor blades used are Schick super stainless injector blades (single-edged). The lower blade-supporter for the angled blades (part no. 4), is then placed over the horizontally held blades. Two blades are then inserted and the upper blade-supporter (part no. 3) holds these in place when the assembly nut (part no. 2) is screwed down (left-hand thread). A clip (part no. 1) is used to prevent the angled blades from bending outwards under centrifugal force. Without the clip the blades tend to cut into the side of the glass vessel during blending, which can break the blades and weaken the glass.

The machine drawings for the new parts are given in Figures 2 and 3. All parts have been made of stainless steel, which is perhaps unsatisfactory for the axle where it is in contact with the bearings in the base. This can be remedied by having the axle hard chromium plated. The part specifications are for adapting the cutting unit of a Braun kitchen homogenizer, model KX32.

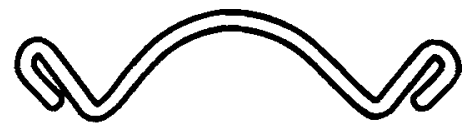

Part no. 1

Scale: 1:1 (can be used as a template) Material : Stainless steel spring wire

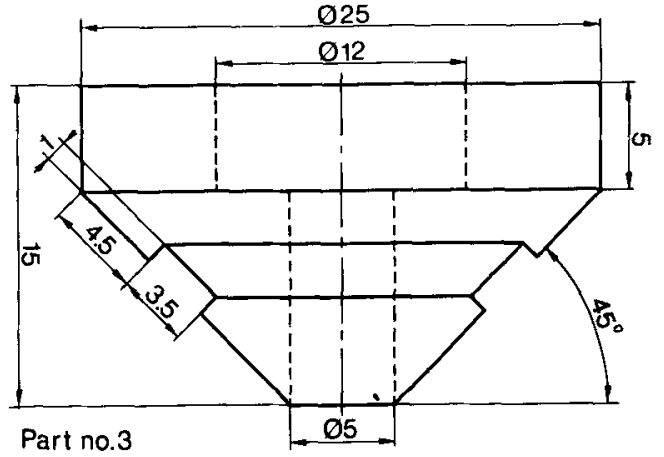

Material: Stainless steel

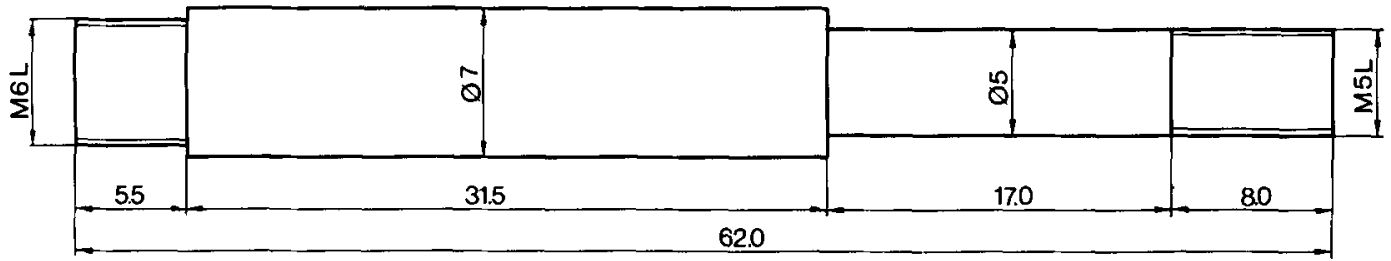

Part no.7

Material: Stainless steel

Figure 2. Machine drawings for the construction of the holding clip (part no. 1), the axle (part no. 7) and the upper blade-supporter (part no.3). Distances in mm. 


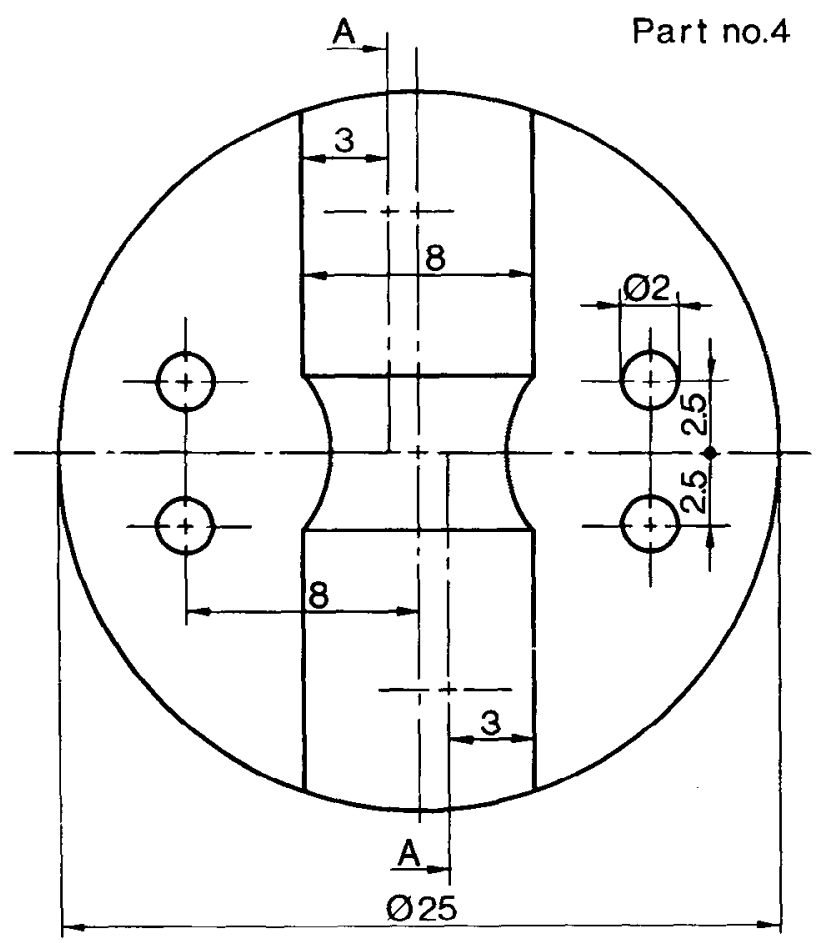

Material : Stainless steel

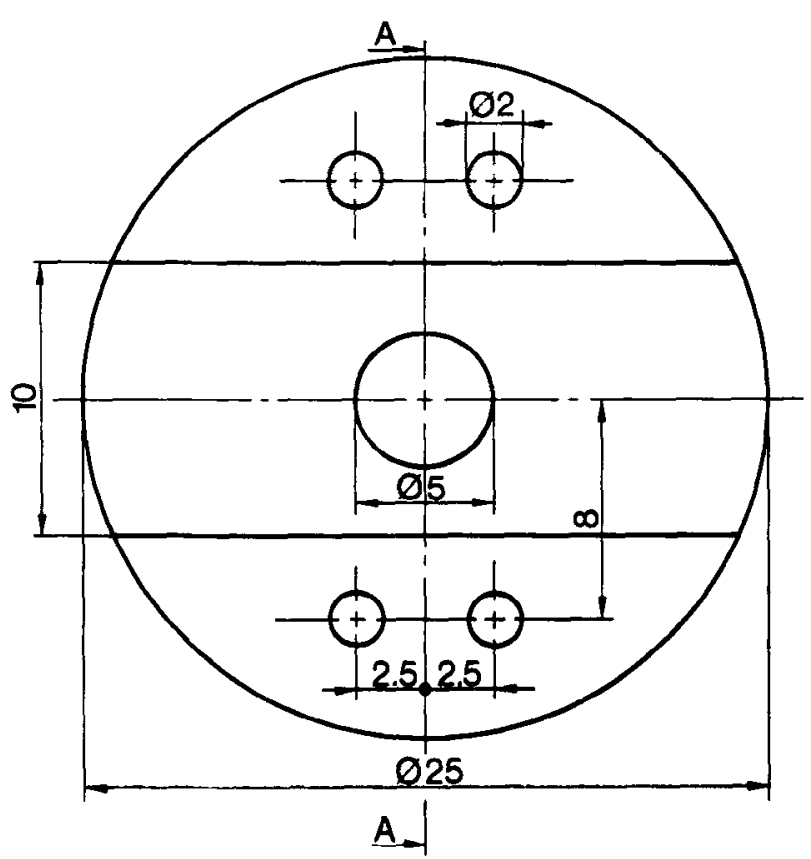

Part no.5

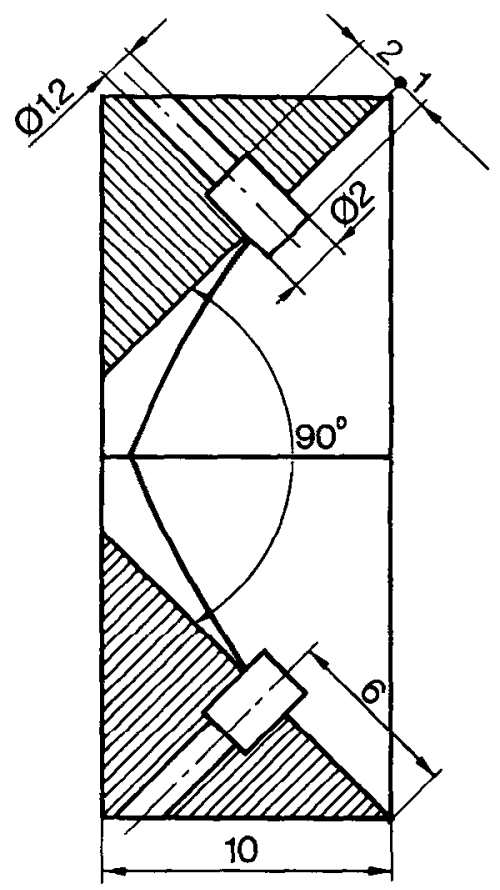

Section AA

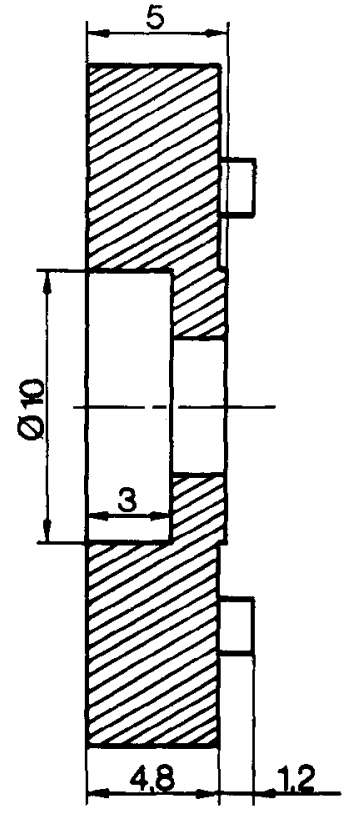

Section AA

Material : Stainless steel

Figure 3. Machine drawings for the construction of the lower blade-supporter (part no. 4) and the bladesupporter for the horizontally held blades (part no. 5). Distances in mm.

Figure 4. Representative field of intact plastids isolated from greening barley seedling leaves. $\times 12,300$ (Bar $=2$ $\mu \mathrm{m})$. 


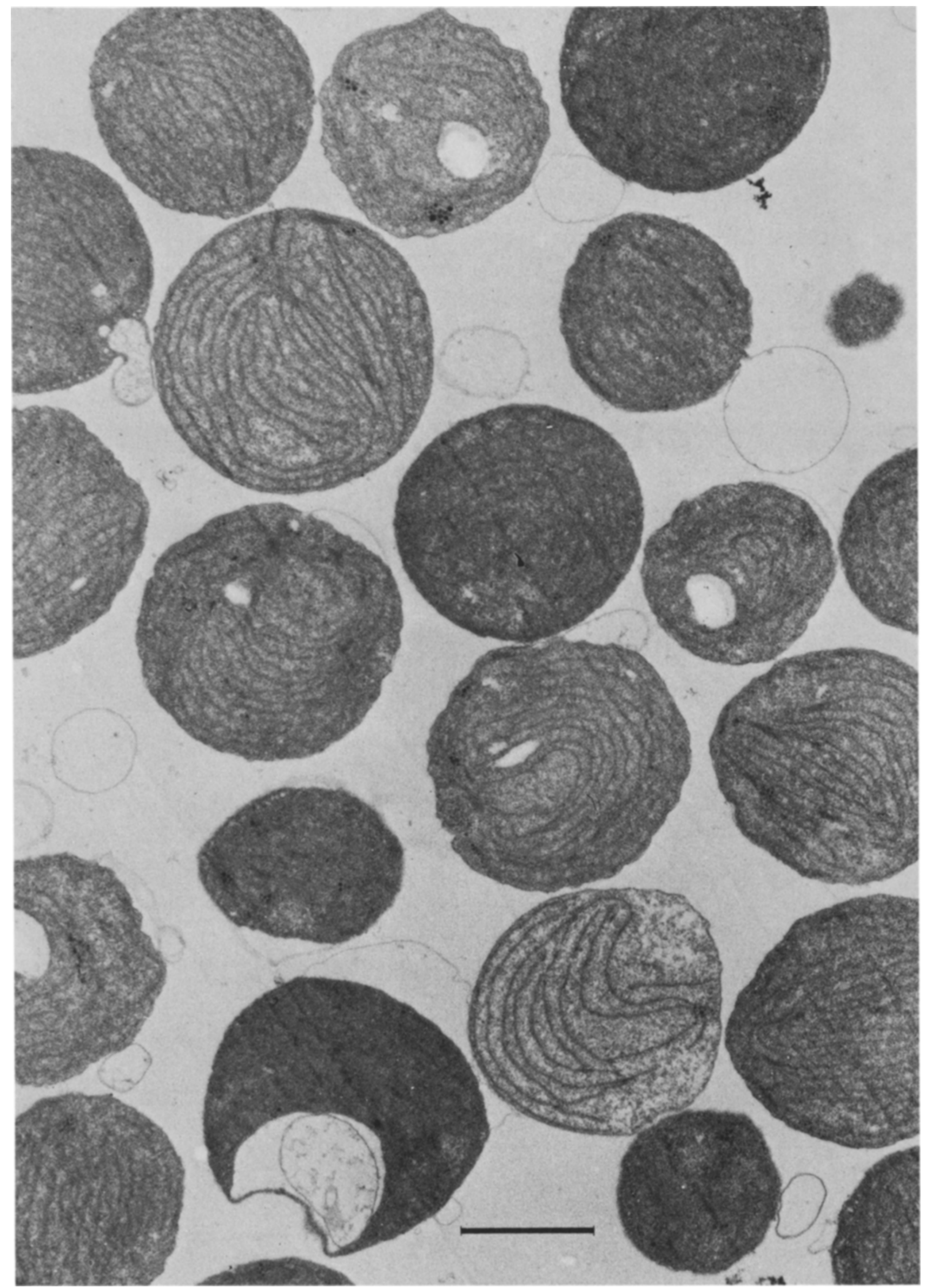




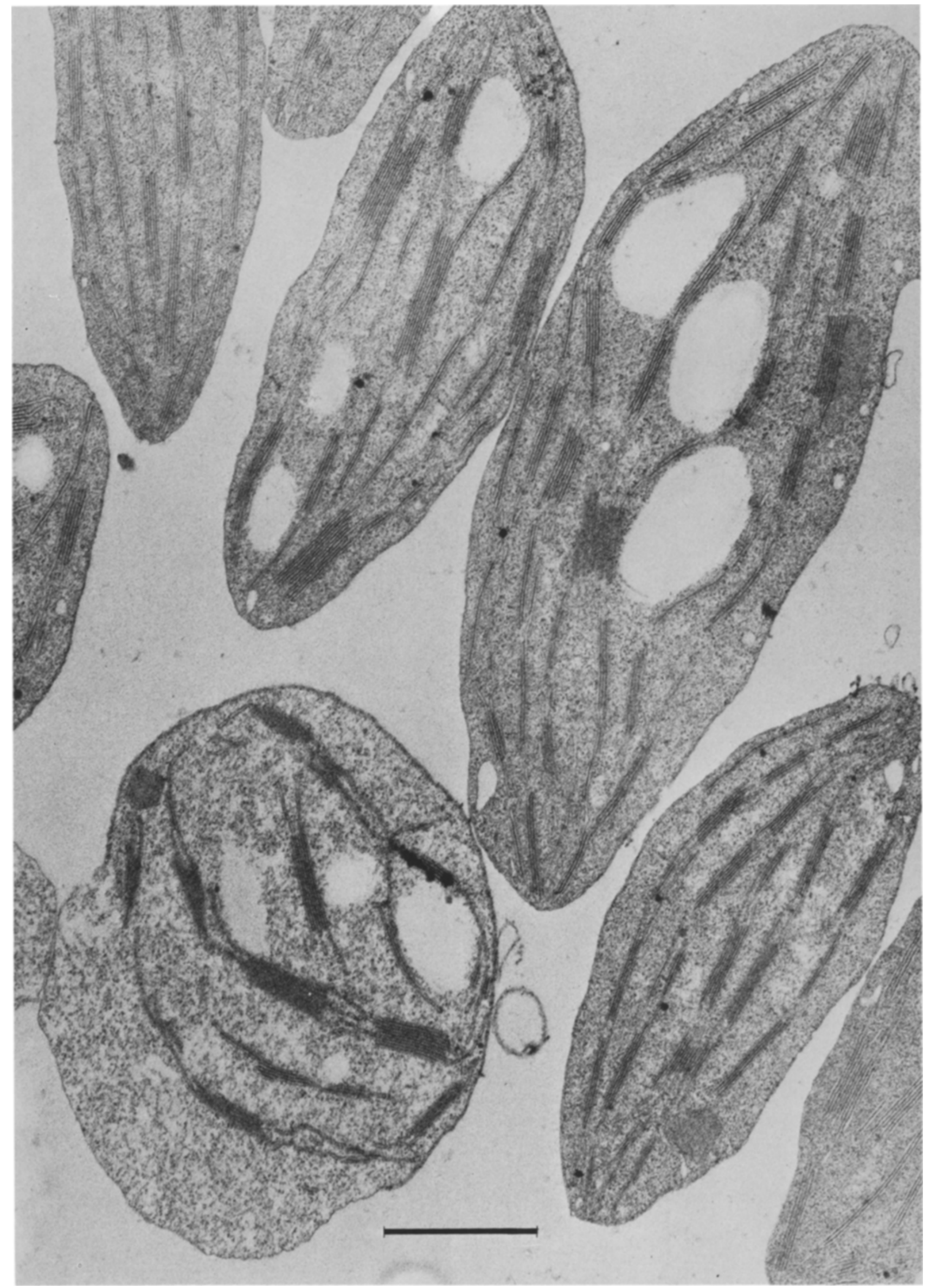




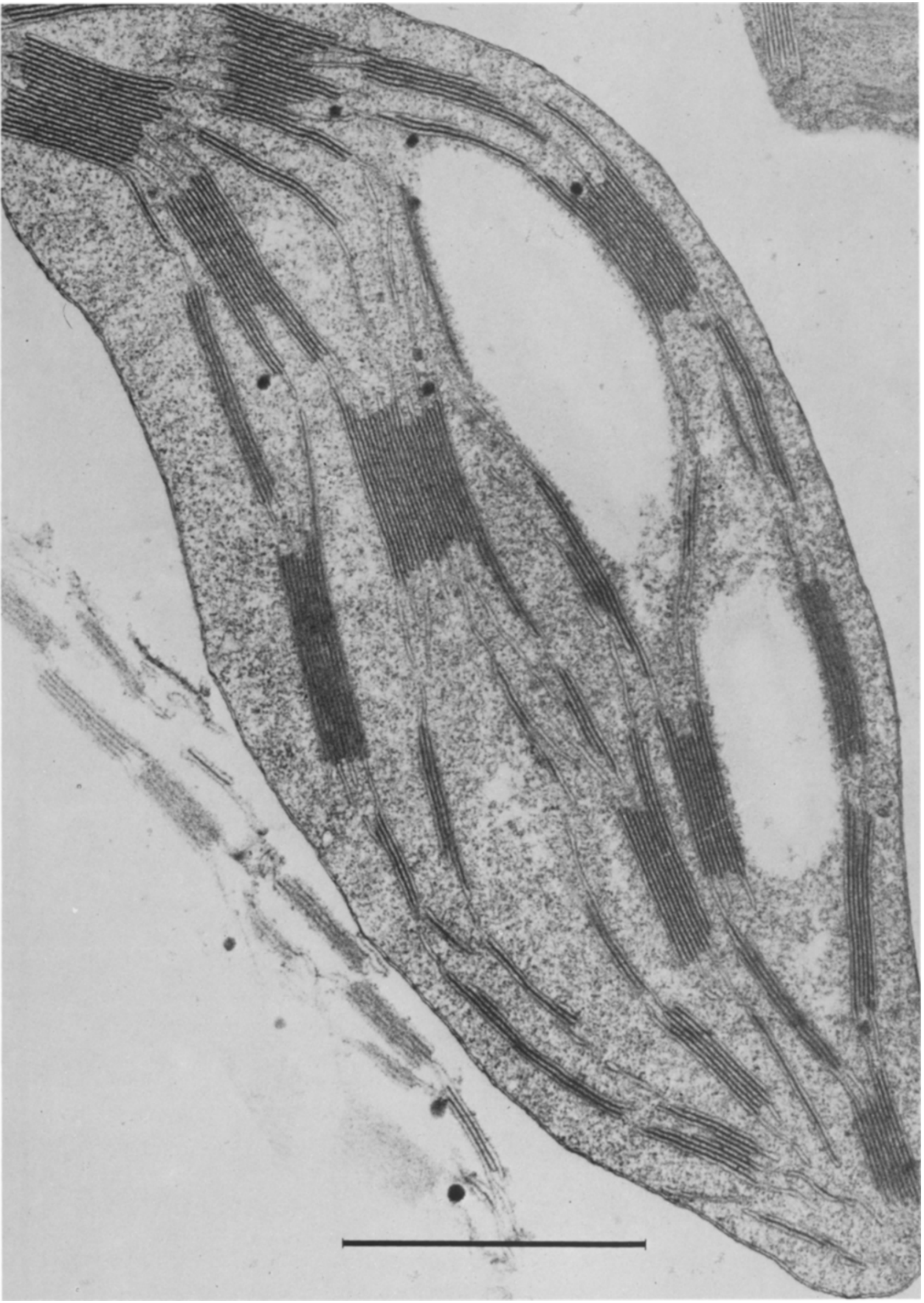


(6.).

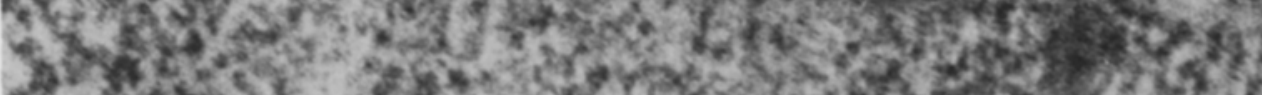

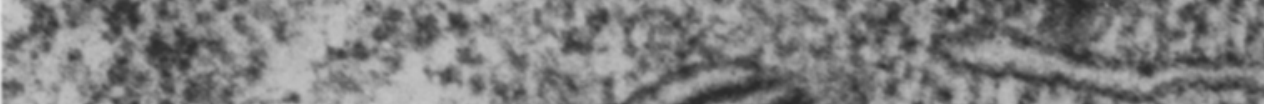

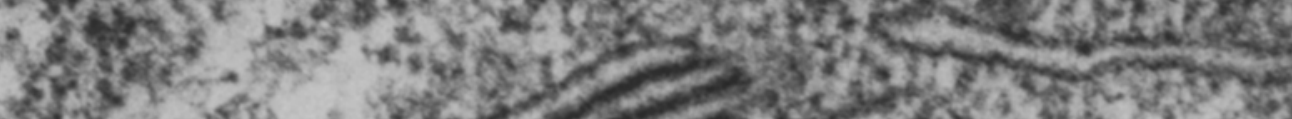

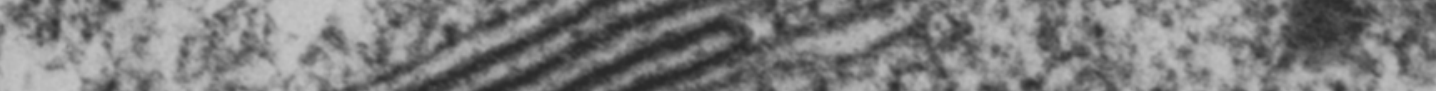

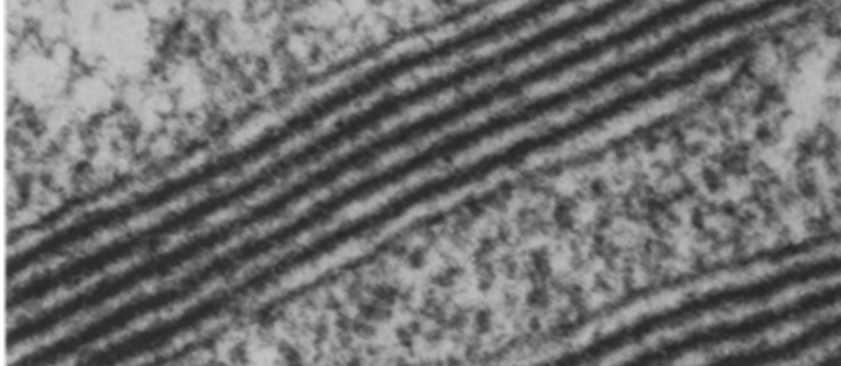

concest 35

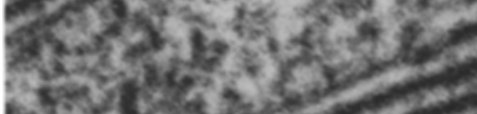

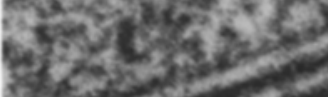

(2).

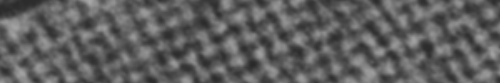

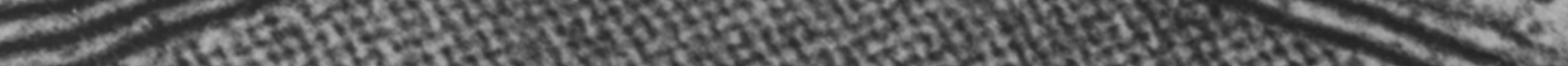

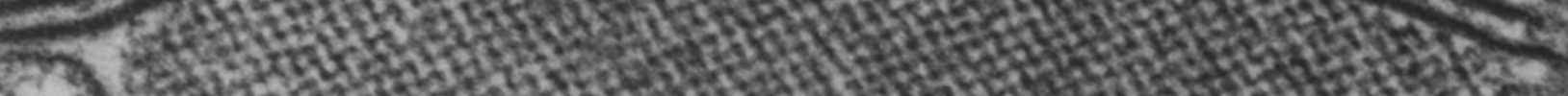

2. 3 .

S.

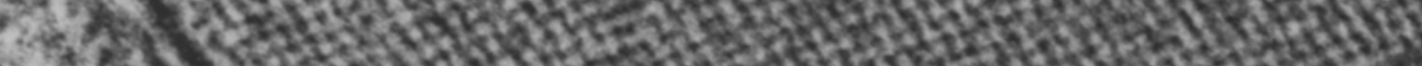

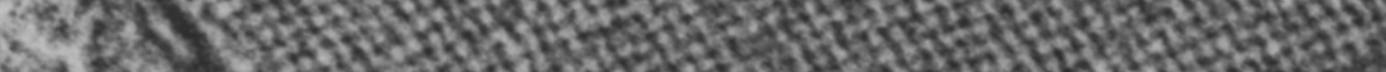

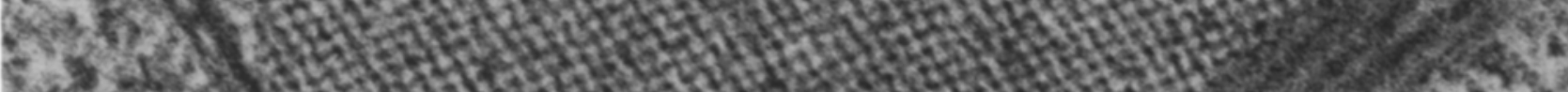

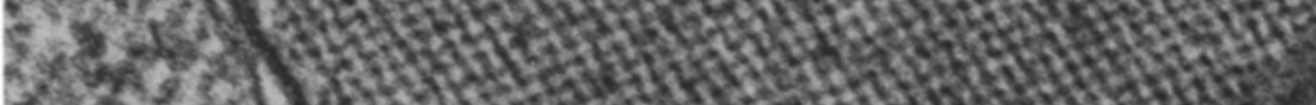

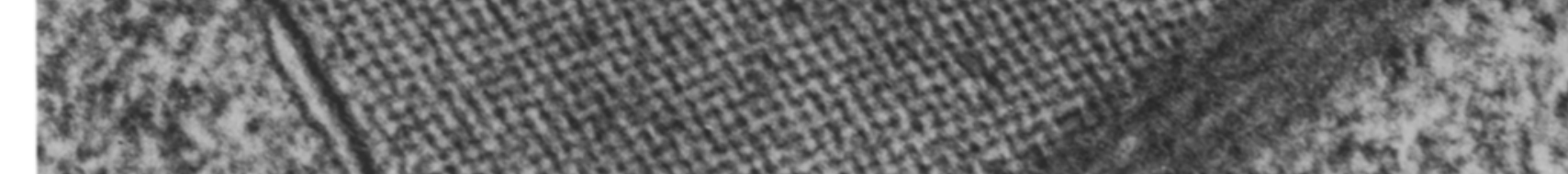

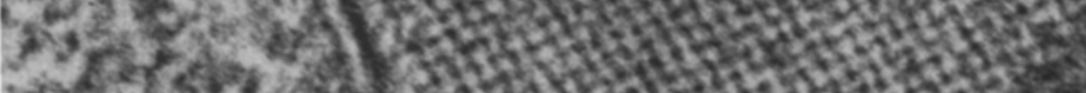

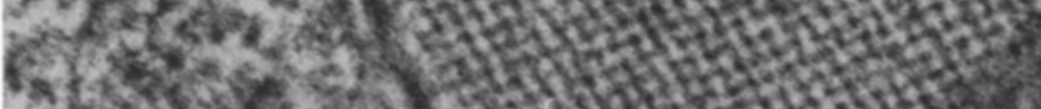

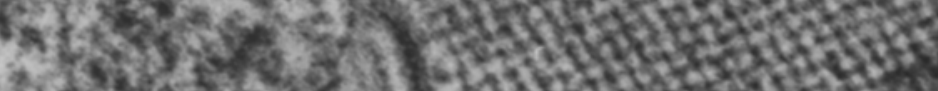

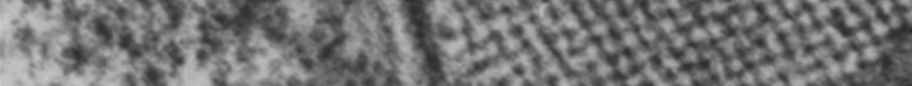

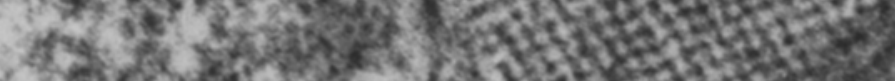

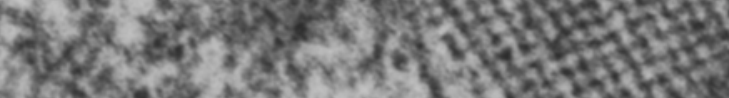

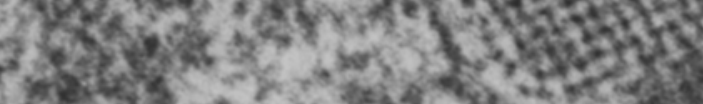

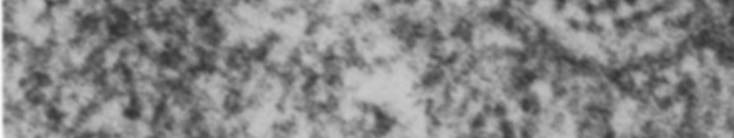

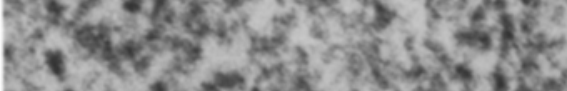

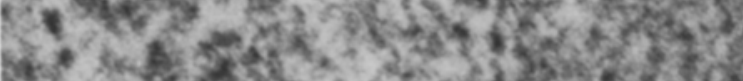

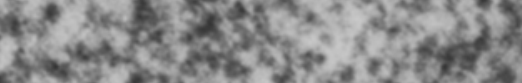

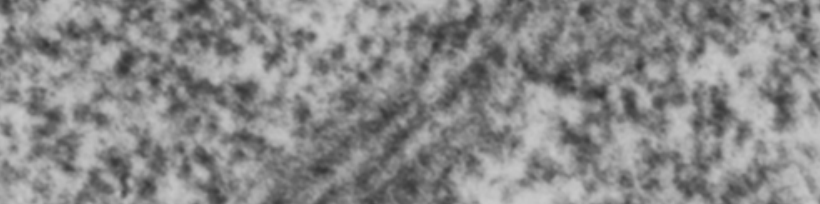

whest

ato

3.

anstist 
Figure 5. Isolated spinach plastids. $\times 28,200($ Bar $=1 \mu \mathrm{m})$.

Figure 6. Higher magnification electron micrograph of an isolated spinach chloroplast demonstrating the intactness of the plastid envelope. $\times 55,500(\mathrm{Bar}=1 \mu \mathrm{m})$.

Figure 7. Detail of internal structures of an isolated spinach chloroplast. Note grana and intrathylakoidal crystal of Fraction I protein (3). $\times 172,000$ (Bar $0.25 \mu \mathrm{m}$ ).

\section{OPERATION OF THE MODIFIED HOMOGENIZER}

Batches of $50 \mathrm{~g}$ of precooled leaves are placed directly in the isolation medium without first cutting into small pieces by hand. Two or three short bursts of power are sufficient to chop the leaves into short lengths, and homogenization is achieved by $15-30 \mathrm{sec}$ at full speed. The resulting slurry is filtered through 31 $\mu$ mesh nylon gauze and plastids isolated as described in an accompanying paper (1). The short, cleanly cut, pieces of fibre in the solid residue indicate efficient homogenization and a low degree of shearing of the tissue. Plastids can be isolated from as little as $25 \mathrm{~g}$ and up to $250 \mathrm{~g}$ of barley seedling leaves per grind. The whole homogenization operation can be carried out within one minute.

\section{Table I}

Recovery of plastids from barley and spinach leaves

\begin{tabular}{l|c|c|c}
\hline & \multicolumn{3}{|c}{$\begin{array}{c}\text { Chlorophyll (\% of leaves) } \\
\text { Plastid } \\
\text { pellet }\end{array}$} \\
Tissue & \multicolumn{1}{|c|}{ Supernatant } & Total \\
\hline Barley etioplasts & $5.7^{*}$ & $11.7^{*}$ & $17.4^{*}$ \\
Barley chloroplasts & 9.3 & 15.3 & 24.6 \\
Spinach chloroplasts & 9.8 & 18.0 & 27.8 \\
\hline
\end{tabular}

* Measured as photoconvertible protochlorophyllide.

\section{RESULTS AND DISCUSSION}

Table I gives the recovery of intact and broken plastids from greening barley seedlings and immature spinach leaves. Blind Freddie can see that the modified homogenizer can be used to isolate intact plastids from barley and spinach with equal efficiency. Electron microscopy of a transverse section through the plastid pellet revealed that the plastids were enclosed by an intact double membrane envelope and had a dense stroma (Figures 4 and 5 of this paper and Figures 5 and 6 in reference 1). Higher magnification of isolated spinach chloroplasts demonstrates the continuity of the envelope (Figure 6) and the preservation of internal structures (Figure 7). These plastids are also biochemically active, as shown by their high capacity for synthesizing $\delta$-aminolevulinic acid and chlorophyll from exogenously added glutamate (1).

\section{ACKNOWLEDGEMENTS}

We thank NINA RASMUSSEN for drawing the figures and JeAN SAGE and ANN-SOFI Steinholtz for techinal assistance. Financial support was provided by USPHS, National Institutes of Health grant GM22051 to professor Diter von WETtSTEIN.

\section{REFERENCES}

1. Kannangara, C. G. \& S. P. Gough: Synthesis of $\delta$-aminolevulinic acid and chlorophyll by isolated chloroplasts. Carlsberg Res. Commun. 42, 441-458 (1977)

2. Kannangara, C. G., K. W. Henningsen, P. K. StumpF, L.- A. Appelqvist \& D. von Wettstein: Lipid biosynthesis by isolated barley chloroplasts in relation to plastid development. Plant Physiol. 48, 526-531 (1971)

3. SPREY, B. \& C. LAmbert: Lamellae-bound inclusions in isolated spinach chloroplasts II. Identification and composition. Z. Pflanzenphysiol. 83, 227-247 (1977)

4. WALKER, D. A.: Chloroplasts (and grana): aqueous (including high carbon fixation). In: "Methods of Enzymology،. A. San Pietro ed., Academic Press, New York. Vol. 23, pp. 211-220(1971) 